\title{
Caracterização preliminar da qualidade das águas subterrâneas do Projeto Assentamento Gamaliel, Cuiabá-MT.
}

\author{
Preliminary characterization of the groundwater quality of the Settlement Project \\ Gamaliel , Cuiaba -MT
}

\section{Resumo}

\author{
Isael Minson Gomes $\left.{ }^{1 *}\right)$ \\ Renato Blat Miglinorini²
}

O Projeto Assentamento Gamaliel (PAG) compreende uma área de aproximadamente 2,46 km², localizado na zona rural do município de Cuiabá-MT, próximo ao bairro Altos da Glória. Em 2008, foram assentadas 175 famílias em lotes de 1,2 ha, onde o abastecimento público de água é efetuado somente por poços tubulares. O crescimento demográfico urbano avança em direção ao assentamento, podendo trazer, num futuro próximo, impactos na qualidade e quantidade da água subterrânea no PAG. Diante dessa situação, este trabalho teve por objetivo principal realizar um estudo hidroquímico dessas águas a partir de campanhas de campo e laboratório, caracterizando propriedades físicas e químicas dos recursos hídricos subterrâneos na localidade. As amostras foram coletadas e analisadas entre maio e junho de 2015 e, seguindo metodologia de análises do Standard Methods for the Examination of Water and Wastwater, determinou-se cálcio, potássio, sódio, magnésio e ferro - por espectrometria ótica de emissão atômica com plasma indutivamente acoplado (ICP-OES) -, cloreto, nitrato e sulfato - por cromatografia iônica (IC) - , alcalinidade total - por titulometria, e $\mathrm{pH}$, condutividade elétrica e temperatura - medidos em sonda multiparâmetro. Os dados foram tratados estatisticamente com auxílio do programa IBM $^{\oplus}$ SPSS Statistics v. 24.0 e análise hidroquímica com ajuda do programa Qualigraf ${ }^{\circledR}$ v.1.17. Os resultados mostraram águas quimicamente semelhantes, com sete amostras, classificadas como águas bicarbonatadas magnesianas e uma como bicarbonatada cálcica, hipotermais, neutras a alcalinas, com médio teor de cálcio e magnésio, o que reflete a geologia do Grupo Cuiabá, sendo também isentas de ferro, apesar da ocorrência de piritas na região. São de boa qualidade para consumo humano, agricultura e pecuária.

Palavras-chave: Águas subterrâneas. Hidroquímica. Assentamento Gamaliel. Grupo Cuiabá.

\section{Abstract}

The Projeto Assentamento Gamaliel (PAG) comprises an area of approximately 2.46 $\mathrm{km}^{2}$, located in the countryside of the city of Cuiabá, near the Glory Altos district. In 2008,175 families were settled on plots of $1.2 \mathrm{ha}$, where public water supply is made

I Esp.; Químico; Mestre em Recursos Hídricos da Universidade Federal de Mato Grosso, UFMT; Programa de PósGraduação em Recursos Hídricos; Endereço:Avenida Fernando Correa da Costa, 2367, Boa Esperança, CEP 780860-900, Cuiabá-MT, Brasil; Email: isael.minzon@ifro.edu.br (*) Autor para correspondência.

2 Dr., Geólogo; Professor Associado da Faculdade de Geociências da Universidade Federal de Mato Grosso, Programa de Pós-Graduação em Recursos Hídricos; Endereço: Avenida Fernando Correa da Costa, 2367, Boa Esperança, CEP 780860-900, Cuiabá-MT, Brasil; Email: rena@ufmt.br.

Recebido para publicação em 10/10/2016 e aceito em II//2/2019

\begin{tabular}{lllllll}
\hline Ambiência & Guarapuava (PR) & v.I5 n.2 & p. $457-474$ & Maio/Ago 2019 & ISSN I808 - 025I
\end{tabular}


only by wells. The urban population growth progresses toward the settlement and can bring in the near future impacts on the quality and quantity of groundwater in the PAG. Given this situation, this study had the main objective to perform a hydrochemical study of groundwater from field surveys and laboratory, featuring physical and chemical properties of groundwater resources in the locality. The samples were collected and analyzed between May and June 2015, and following analysis methodology of the Standard Methods for the Examination of Water and Wastwater (2012) was determined calcium, potassium, sodium, magnesium and iron by optical spectrometry atomic emission inductively coupled plasma (ICP-OES), chloride, nitrate and sulfate by ionic chromatography (IC), total alkalinity by titration, and $\mathrm{pH}$, electrical conductivity and temperature measured in multiparameter probe. The data were statistically analyzed with the help of IBM ${ }^{\circledast}$ SPSS Statistics program v. 24.0 and hydrochemical analysis with the help of Qualigraf program v. 1.17. The results showed chemically similar waters, with seven samples classified as magnesian bicarbonate waters and as calcium bicarbonate, hypothermal, neutral to alkaline, with an average calcium and magnesium content, which reflects the geology of the Cuiabá Group and is also free of iron, despite the occurrence of pyrites in the region. They are of good quality for human consumption, agriculture and livestock.

Keywords: Underground water. Hydrochemistry. Gamaliel Settlement. Cuiabá Group.

\section{Introdução}

Um importante fator na evolução de povos e nações é a disponibilidade de água. Em lugares onde ela é acessível, as civilizações geralmente desenvolvem-se energicamente e onde ocorre determinado déficit hídrico, o crescimento populacional é deficiente.

O desenvolvimento socioeconômico e a acelerada urbanização, ocorrida a partir da segunda metade do século XX, impulsionaram aumentos consideráveis no consumo de água. Proporcionalmente aumentaram os impactos quantitativos e qualitativos sobre esse recurso. Estima-se que, em 2030, a população mundial seja de aproximadamente 8,5 bilhões de pessoas, e de 9,7 bilhões em 2050 (CENTRO REGIONAL DE INFORMAÇÕES DAS NAÇÕES UNIDAS, 2015), o que afetará em qualidade e quantidade os recursos hídricos.

A maior reserva estratégica de água doce em todo o mundo são as águas subterrâneas. O Brasil é detentor de $8 \%$ da água doce do mundo, dos quais 112 bilhões de $\mathrm{m}^{3}$ são água subterrânea (HIRATA; SUHOGUSOFF, 2003). Apesar da disponibilidade qualitativa e quantitativa, com baixo custo de exploração, a importância das águas subterrâneas não é totalmente reconhecida, nota-se a perfuração indiscriminada de poços, fiscalização pública insuficiente e descaso quanto à proteção das áreas de recarga dos aquíferos, tornando-as mais vulneráveis em diversas regiões brasileiras.

As águas subterrâneas possuem características físicas e químicas que são o resultado das condições do meio em que se encontram, variáveis no tempo e no espaço (RAVE, 2009).

A mobilidade geoquímica dos elementos dissolvidos na água relaciona-se com a capacidade de fluxo no arranjo litosfera-biosfera-hidrosfera-atmosfera, submetendo-se ainda a fatores como a habilidade do elemento participar de interações de troca iônica, com a litosfera e a biosfera e da solubilidade, dependente do potencial iônico de cada um dos íons (RAMAGE, 2005). 
Cuiabá, como as grandes cidades brasileiras apresentou, nos últimos quinze anos, um notável crescimento populacional, de aproximadamente 20\% (IBGE, 2000; IBGE, 2010), que infelizmente não tem sido acompanhado por investimentos necessários em infraestrutura, como por exemplo, no saneamento básico, onde apenas 45,61\% da população é atendida por rede de esgoto (SNIS, 2014).

Outro aspecto importante é a hidrogeologia da região, a qual mostra que os aquíferos em Cuiabá são do tipo livre em meio fraturado (MIGLIORINI; SILVA, 2000), que notadamente apresentam maior vulnerabilidade à contaminação.

Diante dessa situação, este trabalho visa caracterizar a qualidade da água subterrânea numa área de assentamento rural, como também auxiliar na conservação e gestão dos recursos hídricos subterrâneos em Cuiabá-MT.

\section{Localização}

O Projeto Assentamento Gamaliel se encontra na zona rural do município de Cuiabá-MT, a aproximadamente $10 \mathrm{~km}$ do centro urbano, próximo ao bairro Altos da Glória, região norte da capital mato-grossense, a 15³1'27.3” de longitude sul e 5600'25.5” de latitude oeste (Figura 1).

\section{Geologia}

Cuiabá encontra-se sobre a unidade litoestratigráfica Grupo Cuiabá, descrita primeiramente por Evans (1894), chamada inicialmente de Cuyaba Slates. Almeida (1964) individualizou o Grupo Cuiabá como uma unidade litoestratigráfica, sendo também o primeiro a reconhecer essa faixa de dobramentos marginais ao Cráton, propondo a designação Geossinclíneo Paraguai para agrupar as três zonas estruturais que a compõem: Zona da Baixada do Alto Paraguai, da Província Serrana e Baixada Cuiabana.

Luz et al. (1980) e Souza (1981) individualizaram oito subunidades litoestratigráficas para o Grupo Cuiabá, baseando-se nos resultados dos mapeamentos geológicos nas escalas 1:50.000 e 1:250.000 do Projeto Coxipó.

Migliorini (2000) realizou um mapeamento sistemático abrangendo a área urbana de Cuiabá e Várzea Grande e propõe como unidades estratigráficas as formações Miguel Sutil e Coxipó, ambas baseadas especialmente na caracterização estrutural, litológica e estratigráfica.

O Grupo Cuiabá é estruturado pelas formações Rio Coxipó e Miguel Sutil (Tabela 1), caracteriza-se por uma sequência predominantemente de filitos com intercalações de quartizitos, metagrauvacas, metarenitos, metaconglomerados, com raras ocorrências de metacalcários e filitos calcíferos (MIGLIORINI, 2000).

A Formação Miguel Sutil corresponde à subunidade 05 do Projeto Coxipó (LUZ et al., 1980), aflora praticamente em toda porção central e norte das cidades de Cuiabá e Várzea Grande. Foi individualizada por Migliorini (2000) em dois conjuntos faciológicos com base nas estruturas sedimentares e na constituição litológica dominante: Litofácies Pelítica com Laminação Plano-paralela e Litofácies argilo-areno-conglomerática. A primeira corresponde a metargilitos ou filitos de cor cinza esverdeada a marrom avermelhada, normalmente sericíticos, sendo frequentes as laminações plano-paralelas centimétricas a milimétricas. A Litafácie argiloareno-conglomerática corresponde às sequencias cíclicas granodecrescentes, que descrevem arranjos lenticulares principalmente segundo a direção N30 - $40^{\circ} \mathrm{E}$. Esses conjuntos faciológicos, formados por lentes métricas a quilométricas fazem contato do tipo abrupto e irregular com a 
Figura 1 - Mapa de Localização da Área de Estudo.
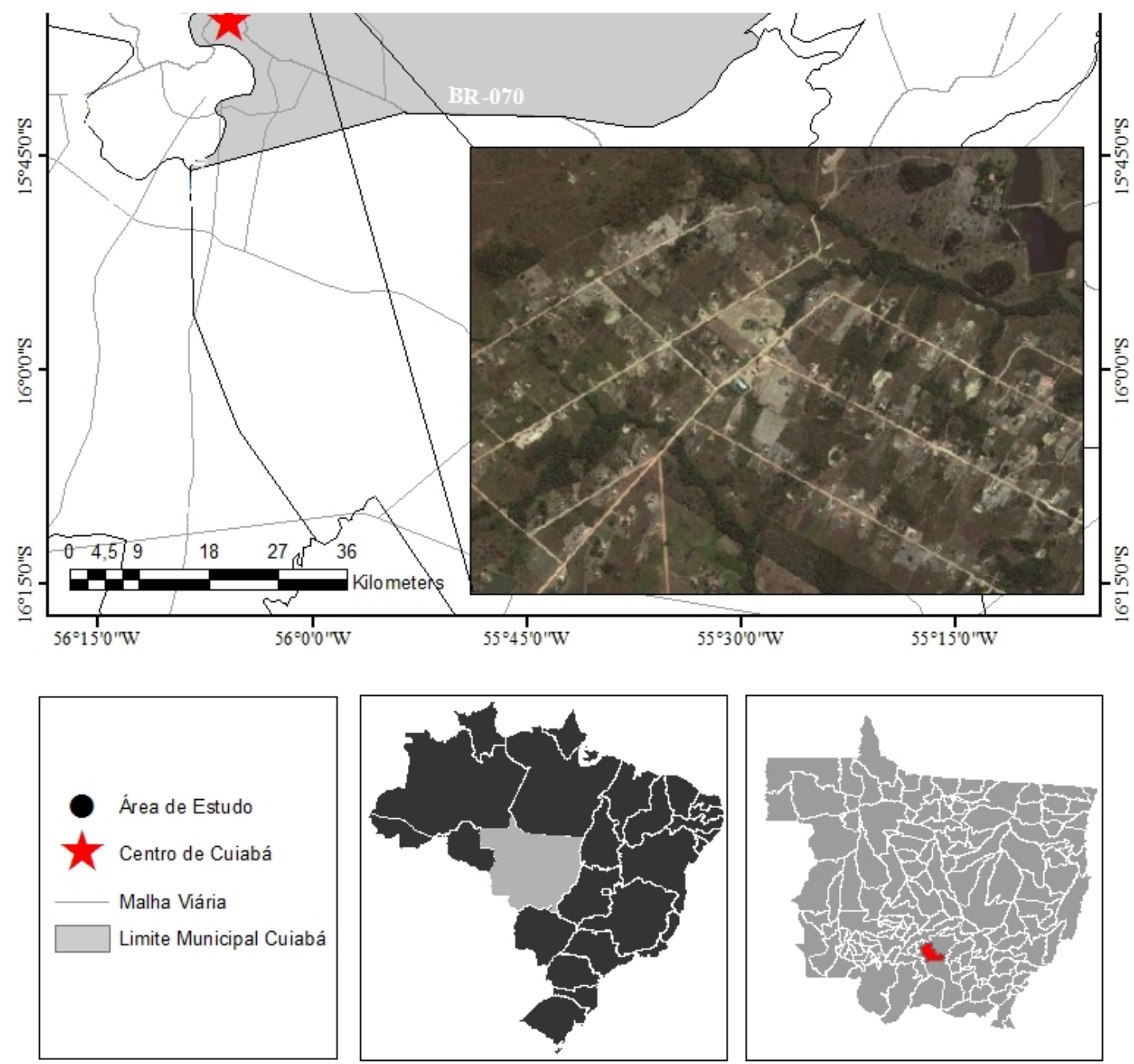

Fonte: BRASIL, 2015 (modificado).

Tabela 1 - Coluna estratigráfica do Grupo Cuiabá na cidade de Cuiabá-MT.

\begin{tabular}{|c|c|c|c|c|}
\hline \multirow[b]{2}{*}{ Era } & \multirow[b]{2}{*}{ Período } & \multicolumn{2}{|r|}{ Unidades } & \multirow[b]{2}{*}{ Litologias } \\
\hline & & Grupo & Formação & \\
\hline \multirow{2}{*}{ 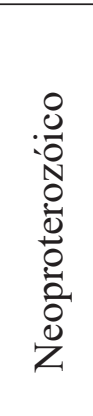 } & \multirow{2}{*}{ 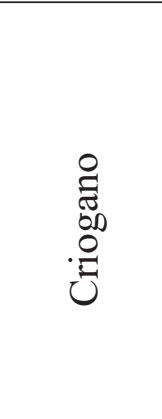 } & \multirow{2}{*}{ 菍 } & Rio Coxipó & $\begin{array}{c}\text { Litofácies Metadiamictito de Matriz } \\
\text { Argilosa } \\
\text { Litofácies Metadiamictito de Matriz } \\
\text { Arenosa } \\
\text { Lifofácies Arenito Quartzosas }\end{array}$ \\
\hline & & & Miguel Sutil & $\begin{array}{l}\text { Litofácies Pelítica Laminada } \\
\text { Litofácies Areno-conglomerática }\end{array}$ \\
\hline
\end{tabular}

Fonte: Modificado de Migliorini (2000). 
Litofácie Pelítica, sendo comuns fragmentos de filitos desta, aparecerem com constituintes de seus níveis conglomeráticos basais.

A Formação Rio Coxipó corresponde à subunidade 06 (LUZ et al., 1980), sobrepondo-se à Formação Miguel Sutil por meio de contatos transicionais e tectônicos, aflorando, principalmente, na porção sul dos municípios de Cuiabá e Várzea Grande. A partir de um mapeamento sistemático, Migliorini (2000) individualizou também duas associações litológicas dominantes. A Unidade I corresponde a Litofácies dos metadiamictitos com matriz argilosa: corresponde a metadiamictitos maciços, cinza esverdeados a amarelados, com matriz argilo-siltosa micácea, em parte feldspática. Camadas tabulares e lentes de metarenitos quartzosos de granulação fina a média, de cor esbranquiçada, com estratificações plano-paralelas e maciços, ocorrem intercaladas aos metadiamictitos. A Unidade II corresponde às Litofácies dos metadiamictitos com matriz arenosa: encontrada, principalmente, na região do Parque Industrial e no bairro Pascoal Ramos, em Cuiabá. São porções do topo da Formação Rio Coxipó. Compõe-se por metadiamictitos maciços, de matriz arenosa e, mais raramente, silto-argilosa, com dimensão e composição mais variadas. A matriz caracteriza-se com uma areia grossa à média, principalmente, de composição quartzosa.

A área do PAG está localizada na Formação Rio Coxipó do Grupo Cuiabá, destacando-se a Unidade II como constituição litológica dominante.

\section{Hidrogeologia}

Os aquíferos da região de Cuiabá são do tipo livre em meio fraturado, com intensa variação lateral e em profundidade. A matriz do corpo rochoso é caracterizada pela inexistência e/ou presença reduzida de espaços intergranulares. A água subterrânea encontra-se, preferencialmente, nas descontinuidades das rochas como fraturas, fissuras, diáclases e outras, isto é, nas porosidades secundárias. A trama e intensidade dessas descontinuidades definem o potencial do aquífero (MIGLIORINI, 2000).

Há variações extremas de litologia e estrutura proporcionando caráter aleatório das fraturas associadas às zonas produtoras de água subterrânea em pontos preferenciais que proporcionam ao Grupo Cuiabá a ocorrência de zonas aquíferas (MIGLIORINI, 2000).

Migliorini (2000) propõe dois sistemas aquíferos, um poroso (no solo e manto de alteração) e outro no meio fraturado (rochas). Individualiza dois domínios hidrogeológicos no meio fraturado. Um é o domínio da Formação Miguel Sutil, o outro é o da Formação Rio Coxipó. No primeiro domínio, a litofácies argilo-areno-conglomerática apresenta as melhores condições aquíferas e no segundo domínio, os metadiamictitos com matriz arenosa apresentam as melhores condições aquíferas (a região estudada encontra-se nesse domínio).

A produtividade das zonas aquíferas dependerá das características do manto de alteração e do grau de fraturamento das rochas. As melhores situações são aquelas com um manto de alteração predominantemente arenoso, com grande espessura, sobreposto a rochas com elevado grau de fraturamento. Situações intermediárias e em diferentes proporções podem ser encontradas (MIGLIORINI, 2000).

\section{Material e Métodos}

O levantamento das informações teve início com uma pesquisa bibliográfica sobre os aspectos do meio físico da região (geologia, hidrologia, hidrogeologia), hidroquímica de águas subterrâneas e por bases cartográficas digitais, como Mapas do Ministério do Meio Ambiente, Google Maps ${ }^{\circledR}$, Google Earth $^{\circledR}$ e Google MyMaps ${ }^{\circledR}$, que auxiliaram na elaboração do mapa base da região. 
A metodologia desta pesquisa foi dividida em cinco etapas. Após a ampla pesquisa bibliográfica, foi realizado um trabalho de campo para verificar in loco dados obtidos na fase anterior. Numa terceira etapa de campo, todos os poços profundos do PAG selecionados foram georreferenciados e cadastrados em mapa e caderneta de campo. A seguir, foi realizada a coleta das amostras de água subterrânea, que foram enviadas ao laboratório. Por fim, os resultados foram estudados em escritório.

\section{Etapa de Campo}

Nessa etapa, foram verificadas as condições de acessibilidade aos poços, que também foram georreferenciados. Foram cadastrados 15 poços no mapa base, dos quais um estava inativo e outro em construção.

Em seguida, em 03 de junho de 2015, já com os pontos amostrais catalogados no mapa base, optou-se por uma rota para a coleta das amostras que, logisticamente, permitisse um menor intervalo de tempo em campo.

Além do mapa com a localização dos pontos amostrais, ainda se utilizou caderneta de campo, aparelho com sistema de posicionamento global GPSMAP 78s Garmin, câmera fotográfica Samsung, sonda multiparâmetro Hanna ${ }^{\oplus}$ HI 9829 para executar medidas de condutividade elétrica, $\mathrm{pH}$ e temperatura, frascos de polietileno de 2 litros, luvas de látex e caixas térmicas de isopor com gelo.

A coleta seguiu as metodologias indicadas no Guia de Coletas de Amostras de Água (CETESB, 2011), que orienta para os devidos cuidados quanto à preservação, armazenamento e transporte, a fim de que alterações físico-químicas sejam mínimas.

Para coletar amostras representativas, os poços ficaram jorrando por aproximadamente 20 minutos antes da coleta, evitando-se assim aguas que não condizem com a realidade do aquífero.

Em seguida, na boca do poço, procedeu-se amostragem em frascos de polietileno de 2 litros, e determinação de $\mathrm{pH}$, temperatura da água e condutividade elétrica, em alíquotas separadas.

Então os frascos de coleta, totalmente preenchidos e em duplicatas, foram acondicionados em caixas térmicas com gelo a $5^{\circ} \mathrm{C}$, para preservação e transporte até o laboratório.

Os valores estimados de sólidos totais dissolvidos (STD) foram obtidos de acordo com Matthess (1982).

Dos 15 poços cadastrados, foi possível coletar apenas em 8, devido a ausência dos proprietários, ou em razão da ausência de pontos de coleta na boca do poço.

\section{Etapa de Laboratório}

Dentre os diversos parâmetros físico-químicos que podem ser mensurados em águas subterrâneas, optou-se por cálcio $\left(\mathrm{Ca}^{+2}\right)$, magnésio $\left(\mathrm{Mg}^{+2}\right)$, potássio $\left(\mathrm{K}^{+}\right)$, sódio $\left(\mathrm{Na}^{+}\right)$, ferro total $\left(\mathrm{Fe}^{+2}\right.$ e Fe $\left.{ }^{+3}\right)$, cloreto $\left(\mathrm{Cl}^{-}\right)$, sulfato $\left(\mathrm{SO}_{4}^{-2}\right)$, nitrato $\left(\mathrm{NO}_{3}^{-}\right)$e alcalinidade total.

As análises laboratoriais seguiram metodologia padrão de acordo com o Standard Methods for the Examination of Water and Wastwater (APHA, AWWA, WPCF, 2012).

Como a área de pesquisa é um assentamento rural, com atividades de agricultura familiar como horticultura, piscicultura, bovinocultura e fruticultura, é interessante a classificação da qualidade da água para usos na agricultura e pecuária. Para agricultura utilizou-se a classificação proposta pelo Laboratório de Salinidade dos Estados Unidos (USSL), que se baseia na Razão de Adsorção de Sódio (RAS), como indicador do risco de salinização do solo, calculada a partir do exposto na Equação 1, onde "r" expressa a concentração dos íons em meq $\mathrm{L}^{-1}$ (RICHARDS, 1954): 


$$
\mathrm{RAS}=\frac{\mathrm{rNa}^{+}}{\sqrt{\frac{\mathrm{r}\left(\mathrm{Ca}^{+2}+\mathrm{Mg}^{+2}\right)}{2}}}
$$

Os dados das análises também foram submetidos ao cálculo do balanço da carga iônica nas oito amostras, para o controle de qualidade das análises, uma vez que essa validação é necessária para a plotação dos resultados analíticos em diagramas como os de Piper (1944).

Foi utilizado o programa Qualigraf versão 1.17 da Fundação Cearense de Meteorologia e Recursos Hídricos (MÖBUS, 2014), tanto para a classificação no diagrama de Piper, quanto para a classificação em relação à salinidade para uso na agricultura e para o cálculo do balanço da carga iônica. Os dados estatísticos foram tratados com auxílio do programa IBM $^{\circledast}$ SPSS $^{\oplus}$ Statistics 24.0, estabelecendo nível de confiança de 95\%.

\section{Resultados e Discussão}

Os poços distribuídos no PAG estão plotados em mapa na Figura 2, destacando os pontos em vermelho, que são os poços selecionados para coleta e análises físicas e químicas.

A Figura 3 apresenta, os gráficos dos resultados de $\mathrm{pH}$, temperatura, condutividade elétrica e sólidos totais dissolvidos em amostras de água coletadas em poços no Projeto Assentamento Gamaliel, em Cuiabá-MT, no dia 03/06/2015.

$\mathrm{Na}$ Figura 3, observa-se que os valores de $\mathrm{pH}$ variaram de 7,01 a 8,02 com média de 7,65, desvio padrão de 0,306 e mediana em 7,65, indicando águas subterrâneas variando de neutras a alcalinas.

Valores de $\mathrm{pH}$ elevados podem levar à precipitação de alguns sólidos solúveis na água, como ferro e manganês, que resulta em um barro limoso,obstruindo tubulações em sistemas de irrigação (FEIS,2015).

A Portaria de Consolidação no 5 de 2017 do Ministério da Saúde (BRASIL, 2017) recomenda que se mantenha o $\mathrm{pH}$ entre 6,0 e 9,5 em sistemas de distribuição de água para abastecimento, portanto as águas subterrâneas dos poços do Projeto Assentamento Gamaliel encontram-se naturalmente dentro dos padrões legais brasileiros para o consumo humano.

Apoitia (2003), estudando águas subterrâneas do Grupo Cuiabá, na região de Cuiabá, encontrou águas subterrâneas de ácidas a neutras. Já Migliorini (2000), relatou águas de neutras a alcalinas, como as identificadas neste trabalho.

O Grupo Cuiabá, apresenta lentes de calcário descontínuas (BEAL, 2013), nos quais o cálcio e o magnésio agem como neutralizantes da acidez, particularmente seus carbonatos, óxidos e hidróxidos (SILVA et al., 2009), o que explica o $\mathrm{pH}$ alcalino encontrado, principalmente, quando são correlacionados com os teores de cálcio e magnésio.

A temperatura da água influencia muitos processos físicos, químicos e microbiológicos, como por exemplo, a solubilidade dos gases dissolvidos. Cuiabá localiza-se numa região de altas temperaturas, logo as medidas em água refletiram essa condição. Foram classificadas, segundo Custódio e Llamas (1983), como hipotermais, com média de $29,25^{\circ} \mathrm{C}$, variando de $28,11^{\circ} \mathrm{C}$ a 30,4 ${ }^{\circ} \mathrm{C}$, com desvio padrão de 0,73 e mediana em $29,23{ }^{\circ} \mathrm{C}$, o que pode ser observado na Figura $3 \mathrm{~b}$.

Apoitia (2003) e Migliorini (2000) registram temperaturas das águas subterrâneas semelhantes para e região de Cuiabá. 


\section{Figura 2 - Mapa do PAG com os poços cadastrados.}

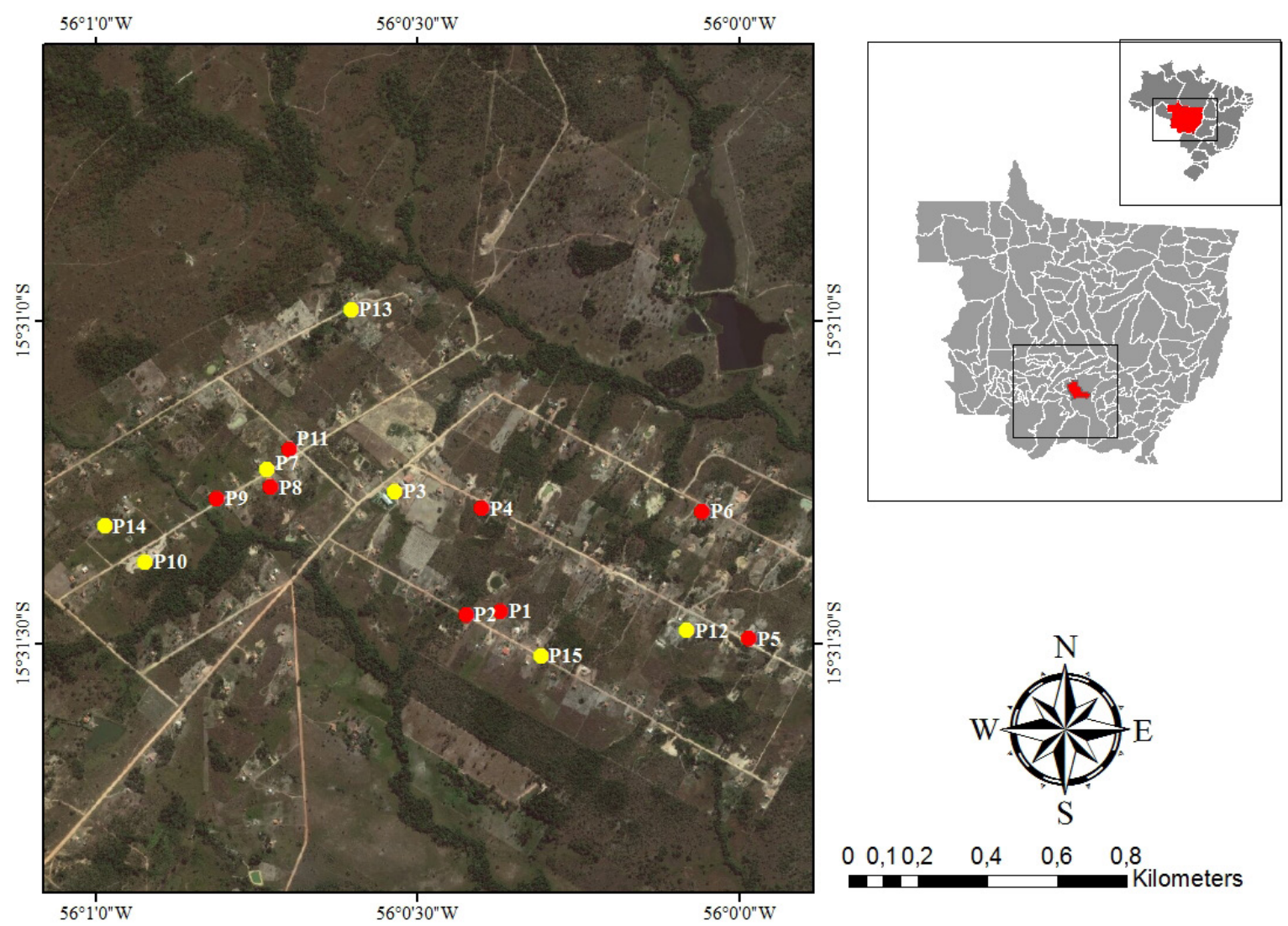

Fonte: BRASIL, 2015 (modificado).

A condutividade elétrica é a capacidade que a água tem de conduzir corrente elétrica e está relacionada à concentração de íons dissolvidos na água, provenientes de seus sais. Depende também, da temperatura, sendo diretamente proporcional a esta. É um parâmetro que permite a visualização de modificações na composição de um corpo hídrico, especialmente na sua concentração mineral, porém não fornece mais informações a respeito das quantidades relativas dos vários componentes.

Comparando-se os valores de condutividade elétrica obtidos neste trabalho com os medidos por Apoitia (2003) percebe-se que também são próximos, pois sua média foi de $398,45 \mu \mathrm{S} \cdot \mathrm{cm}^{-1}$ e desvio padrão de $120,24 \mu \mathrm{S} \cdot \mathrm{cm}^{-1}$, com mediana em $400,50 \mu \mathrm{S} \cdot \mathrm{cm}^{-1}$.

Neste trabalho, os valores estatísticos encontrados foram máximo de $453 \mu \mathrm{S} \cdot \mathrm{cm}^{-1}$, mínimo de 268, com média em $355,5 \mu \mathrm{S} \cdot \mathrm{cm}^{-1}$, mediana de $347 \mu \mathrm{S} \cdot \mathrm{cm}^{-1}$ e desvio padrão igual a $64,58 \mu \mathrm{S} \cdot \mathrm{cm}^{-1}$.

A Figura 4 apresenta as medidas dos cátions detectados em laboratório nas águas subterrâneas do PAG.

O cálcio é elemento muito comum em águas subterrâneas, pois ocorre em diversos minerais como dolomita, calcita, aragonita e em rochas calcárias. $\mathrm{Em} \mathrm{pH}$ alcalino é precipitado como $\mathrm{CaCO}_{3}$, é responsável, em grande parte, pela dureza da água; quando associado a sulfatos e cloretos provoca dureza permanente, e temporária quando a carbonatos. Em águas subterrâneas ou superficiais, sua associação com carbonatos é utilizada para determinação da alcalinidade (FEITOSA et al., 2008). 
Figura 3 - Variação de pH, temperatura, condutividade elétrica e sólidos totais dissolvidos nos poços amostrados no PAG em junho/2015.

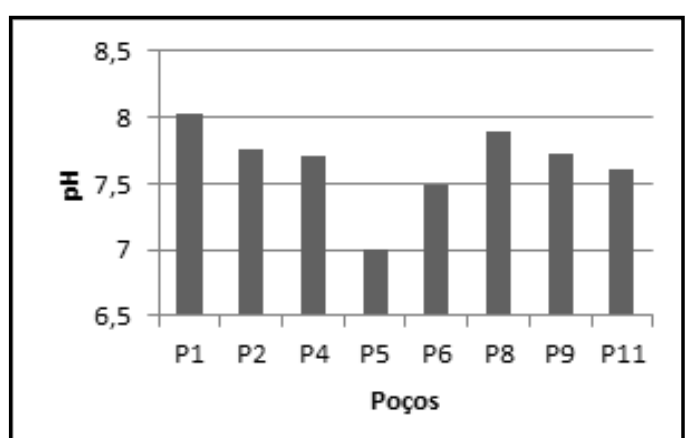

(A)

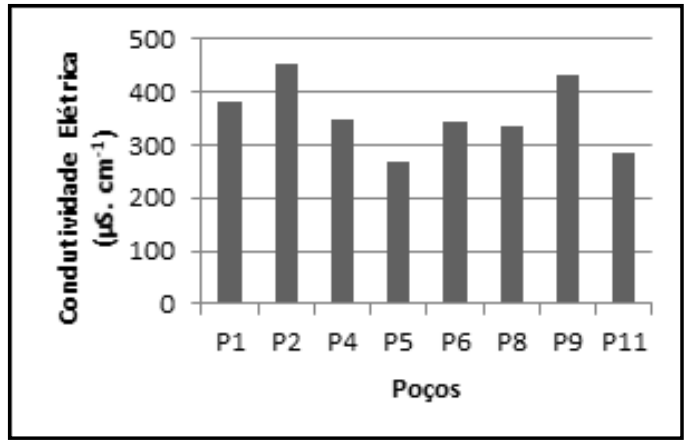

(C)

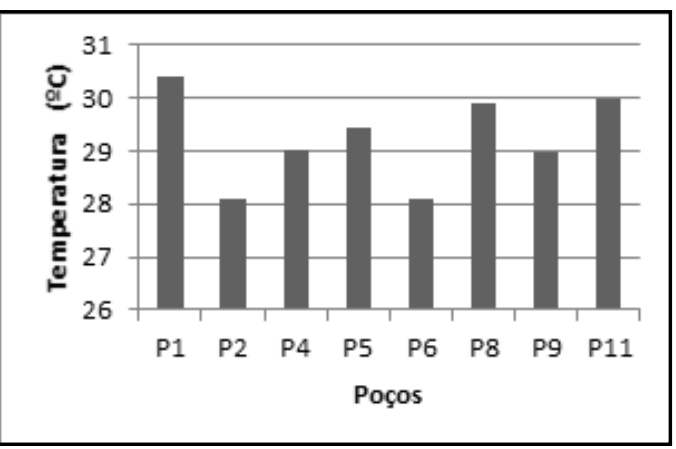

(B)

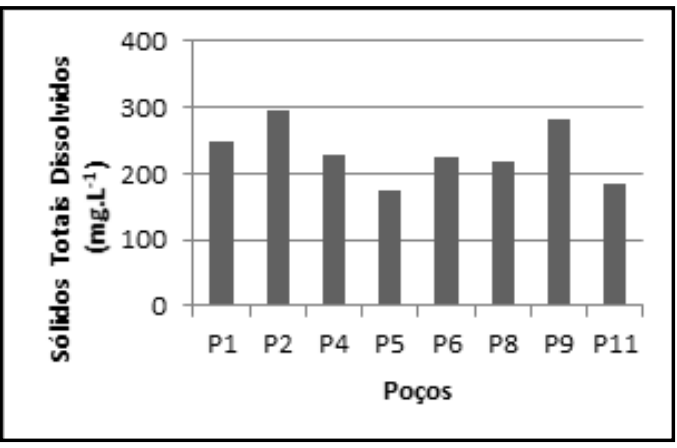

(D)

Fonte: Gomes; Migliorini (2016).

Figura 4 - Concentração dos cátions nos poços amostrados.

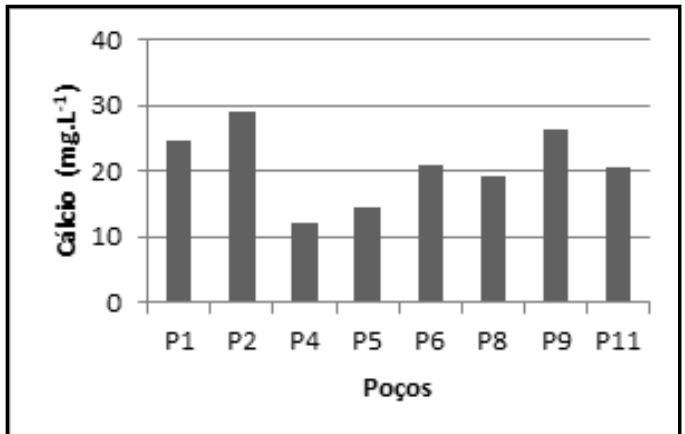

(A)

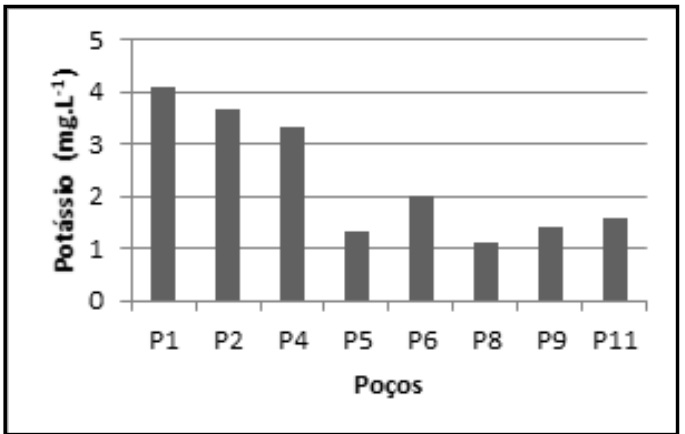

(C)

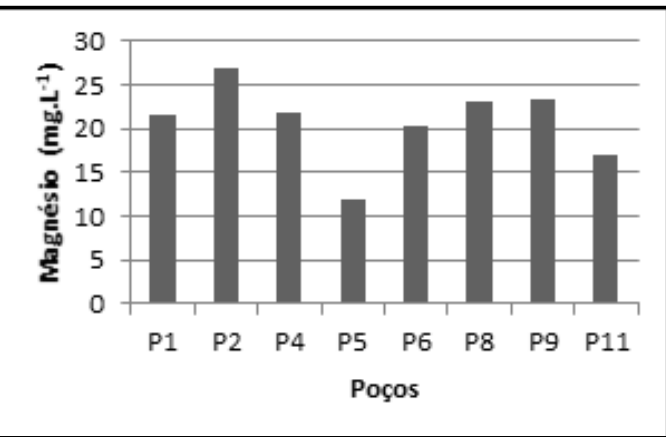

(B)

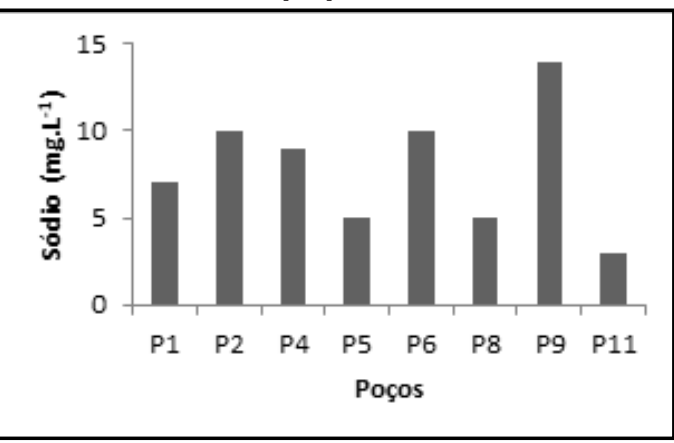

(D)

Fonte: Gomes; Migliorini (2016).

GOMES, I. M., MIGLIORINI, R. B. 
A Figura 4a mostra os valores de cálcio em amostras dos poços estudados. As concentrações, variaram de $12,25 \mathrm{mg} \cdot \mathrm{L}^{-1}$ no poço $\mathrm{P} 4$ a $32,65 \mathrm{mg} \cdot \mathrm{L}^{-1}$ no poço $\mathrm{P} 2$, com média de $20,9 \mathrm{mg} \cdot \mathrm{L}^{-1}$, mediana de 20,71 e desvio padrão de 5,73. São valores que estão dentro do background para a região, quando comparados aos estudos tanto de Apoitia (2003) quanto aos de Migliorini (2000).

$\mathrm{O}$ ponto $\mathrm{P} 2$ é notável pela maior concentração de cálcio, porém essas concentrações não comprometem a potabilidade e a palatabilidade das águas subterrâneas da região. Os valores de cálcio encontrados também podem ser explicados pela presença de lentes de calcário existentes no Grupo Cuiabá.

Amostras com concentrações de cálcio a partir de $70 \mathrm{mg} \cdot \mathrm{L}^{-1}$ conferem sabor de água salobra; o que realmente não foi observado neste estudo, porém os moradores da região queixam-se do sabor da água, como se ela fosse salobra.

O magnésio atua, juntamente com o cálcio, para conferir dureza em águas subterrâneas e superficiais, porém apresenta maior solubilidade que o cálcio, e maior dificuldade de precipitação. O magnésio é, geralmente, lixiviado de minerais como cordiotita, clorita e biotita. As concentrações de magnésio encontradas em águas subterrâneas, geralmente, estão entre 1 e $40 \mathrm{mg} \cdot \mathrm{L}^{-1}$ (CUSTÓDIO; LLAMAS, 1983).

A Figura $4 \mathrm{~b}$ mostra os valores de magnésio nos poços estudados na região do Projeto Assentamento Gamaliel. Neste trabalho, as análises mostraram a concentração mínima de $11,89 \mathrm{mg} \cdot \mathrm{L}^{-1}$ na amostra $\mathrm{P} 5$, enquanto as maiores concentrações de magnésio são dos poços P2, P8 e P9, semelhante aos resultados das concentrações de cálcio, com média em 20,73 $\mathrm{mg} \cdot \mathrm{L}^{-1}$, desvio padrão $4,52 \mathrm{mg} \cdot \mathrm{L}^{-1}$ e mediana $21,6 \mathrm{mg} \cdot \mathrm{L}^{-1}$. As concentrações de magnésio são semelhantes aos resultados obtidos por Apoitia (2003), que obteve média de $16,68 \mathrm{mg} \cdot \mathrm{L}^{-1}$, mínimo $2,2 \mathrm{mg} \cdot \mathrm{L}^{-1}$ e máximo de $30 \mathrm{mg} \cdot \mathrm{L}^{-1}$.

Da mesma maneira que o cálcio, a concentração de magnésio detectada pode ser explicada pela presença de lentes calcárias no Grupo Cuiabá.

O potássio é um elemento pouco observado na água subterrânea, embora seja abundante na crosta terrestre. Isso ocorre devido à intensa atividade do potássio em processos de troca iônica, e por apresentar tendência de fixação em minerais de argila por adsorção, formando minerais secundários. Em águas subterrâneas, as concentrações mais frequentes são menores que $10 \mathrm{mg} \cdot \mathrm{L}^{-1}$ (FEITOSA et al., 2008).

No Projeto Assentamento Gamaliel, as concentrações de potássio determinadas não fugiram à normalidade desse íon em águas subterrâneas como mostra a Figura 4c. Os valores de potássio determinados nas análises foram:, mediana: variaram de $1,13 \mathrm{mg} \cdot \mathrm{L}^{-1}$ a $4,1 \mathrm{mg} \cdot \mathrm{L}^{-1} \mathrm{com}$ média de $2,32 \mathrm{mg} \cdot \mathrm{L}^{-1}$ e desvio padrão $1,18 \mathrm{mg} \cdot \mathrm{L}^{-1}$. Em outros trabalhos a variação foi semelhante: $0,3 \mathrm{a}$ 4,6 mg: $\mathrm{L}^{-1}$ (MIGLIORINI et al., 2000) e 0,5 a 6,6 $\mathrm{mg} \cdot \mathrm{L}^{-1}$ (APOITIA, 2003).

$\mathrm{O}$ sódio é o constituinte maior das rochas ígneas $\left(28.000 \mathrm{mg} \cdot \mathrm{kg}^{-1}\right)$. Ocorre em plagioclásio, principalmente albita $\left(\mathrm{NaAlSi}_{3} \mathrm{O}_{8}\right)$ e é liberado durante o intemperismo desses silicatos (MATHESS, 1982).

O sódio é um dos metais alcalinos mais comuns em águas subterrâneas, principalmente sob a forma de cloretos, com o qual é o responsável pelo aumento constante da salinidade das águas. A concentração média do sódio em águas subterrâneas, normalmente varia de 0,1 a 100 $\mathrm{mg} \cdot \mathrm{L}^{-1}$ (MESTRINHO, 1997).

Apresenta baixa estabilidade química e alta solubilidade, sendo de difícil precipitação quando em solução, facilitando o aumento de sua concentração nas águas, quando equiparado a outros minerais menos solúveis (FEITOSA et al., 2008). 
A Resolução CONAMA no 369/2008 estabelece o limite máximo de $200 \mathrm{mg} \cdot \mathrm{L}^{-1}$ de sódio em águas destinadas ao consumo humano, em virtude de sua relação com a salinidade que, em grandes concentrações, pode limitar o uso da água para consumo humano, uso industrial ou agrícola.

A Figura $4 \mathrm{~d}$ apresenta as concentrações de sódio encontradas nas oito amostras de águas subterrâneas na área de estudo. As concentrações de sódio variaram de $3 \mathrm{mg} \cdot \mathrm{L}^{-1}$ no poço $\mathrm{P} 11$ a $14 \mathrm{mg} \cdot \mathrm{L}^{-1}$ no poço $\mathrm{P} 9$, configurando uma média de $7,87 \mathrm{mg} \cdot \mathrm{L}^{-1}$, mediana de $8 \mathrm{mg} \cdot \mathrm{L}^{-1}$ e desvio padrão de 3,56 mg: $\mathrm{L}^{-1}$. Os valores estão abaixo daqueles encontrados por Apoitia (2003), quando constatou variação de 9,1 a $36 \mathrm{mg} \cdot \mathrm{L}^{-1}$, com média de $21,6 \mathrm{mg} \cdot \mathrm{L}^{-1}$; porém, mais próximos do estudo de Migliorini (2000) que encontrou variação de 0,2 e $5 \mathrm{mg} \cdot \mathrm{L}^{-1}$, com média de 4,58 mg: $\mathrm{L}^{-1}$ em águas subterrâneas do Grupo Cuiabá.

Todas as amostras apresentaram concentrações inferiores ao limite de $200 \mathrm{mg} \cdot \mathrm{L}^{-1}$ estabelecido pela Resolução CONAMA no 369/2008.

$\mathrm{O}$ íon ferroso $\left(\mathrm{Fe}^{2+}\right)$ forma compostos solúveis, principalmente hidróxidos. Em ambientes oxidantes o $\mathrm{Fe}^{+2}$ oxida-se à $\mathrm{Fe}^{3+}$, originando o hidróxido férrico $\left(\mathrm{Fe}\left(\mathrm{OH}_{3}\right)\right)$, substância insolúvel que se precipita, causando o tingimento da água. Assim, águas com altas concentrações de $\mathrm{Fe}^{+2}$ são incolores, mas ao entrarem em contato com o oxigênio do ar ficam amareladas pela oxidação do $\mathrm{Fe}^{2+}$ a $\mathrm{Fe}^{3+}$ (ZIMBRES, 2000).

Em todas as 08 amostras analisadas não foram encontrados teores de ferro maiores que $0,01 \mathrm{mg} \cdot \mathrm{L}^{-1}$, de acordo com o limite de detecção do método de análise utilizado. Apoitia (2003) encontrou valores médios de $0,35 \mathrm{mg} \cdot \mathrm{L}^{-1}$ de ferro total em águas subterrâneas na área urbana de Cuiabá, o que deve estar associado ao solo laterítico e a ocorrência de piritas comum no Grupo Cuiabá. No PAG a presença de cristais de pirita foi observada in loco nos metadiamictitos, porém os resultados analíticos não constataram concentrações maiores de $0,01 \mathrm{mg} \cdot \mathrm{L}^{-1} \mathrm{em}$ suas águas subterrâneas. A média do teor de ferro encontrado por Migliorini (2000) foi $0,78 \mathrm{mg} \cdot \mathrm{L}^{-1}$.

A presença de cloretos em águas subterrâneas pode ser atribuída à dissolução de depósitos salinos como halitas $(\mathrm{NaCl})$ e silvitas $(\mathrm{KCl})$, descargas de efluentes de indústrias químicas, intrusões salinas, etc. Os íons cloreto são altamente móveis e não são retidos em rochas permeáveis. Em argilitos, cristais de $\mathrm{NaCl}$ ou soluções de $\mathrm{NaCl}$ podem ser contidos em poros (CELIGOI, 1999).

É um bom indicador de poluição por aterro sanitário, efluentes domésticos e indústrias (WORLD HEALTH STATISTICS, 2009).

$\mathrm{Na}$ Figura 5 a, é possível verificar uma variação de cloretos de $0,2 \mathrm{mg} \cdot \mathrm{L}^{-1}$ nos poços $\mathrm{P} 4, \mathrm{P} 5$ e P6, até $0,5 \mathrm{mg} \cdot \mathrm{L}^{-1}$ no poço $\mathrm{P} 8$, com média de $0,3 \mathrm{mg} \cdot \mathrm{L}^{-1}$ e desvio padrão igual a $0,106 \mathrm{mg} \cdot \mathrm{L}^{-1}$.

Os valores de cloreto estão bem abaixo do limite recomendado pela Portaria no 5/2017 do Ministério da Saúde (BRASIL, 2017), com a seguinte estatística: variação de 0,2 a $0,5 \mathrm{mg} \cdot \mathrm{L}^{-1}$, média de $0,3 \mathrm{mg} \cdot \mathrm{L}^{-1}$, desvio padrão igual a $0,1 \mathrm{mg} \cdot \mathrm{L}^{-1}$ e mediana de $0,3 \mathrm{mg} \cdot \mathrm{L}^{-1}$. Outros estudos no Grupo Cuiabá registraram valores de concentrações de cloreto bem maiores, com a variação de 24,1 mg: $\mathrm{L}^{-1}$ a $66,6 \mathrm{mg} \cdot \mathrm{L}^{-1}$ e média de 38,46 mg $\cdot \mathrm{L}^{-1}$ (APOITIA, 2003), e com variação de 1 $\mathrm{mg} \cdot \mathrm{L}^{-1}$ a $66,84 \mathrm{mg} \cdot \mathrm{L}^{-1}$ e média de $12 \mathrm{mg} \cdot \mathrm{L}^{-1}$ (MIGLIORINI, 2000).

A dissolução e oxidação de solos e rochas sulfatadas e a lixiviação de compostos ricos em enxofre tornam os íons sulfato mais abundante em águas subterrâneas (FEITOSA et al., 2008). Teores muito altos podem indicar a contaminação por esgotos domésticos, industriais ou por procedimentos agrícolas; normalmente sua concentração em águas subterrâneas é inferior a 100 $\mathrm{mg} \cdot \mathrm{L}^{-1}$ (MESTRINHO, 1997). 
Figura 5 - Concentração dos ânions nos poços amostrados.

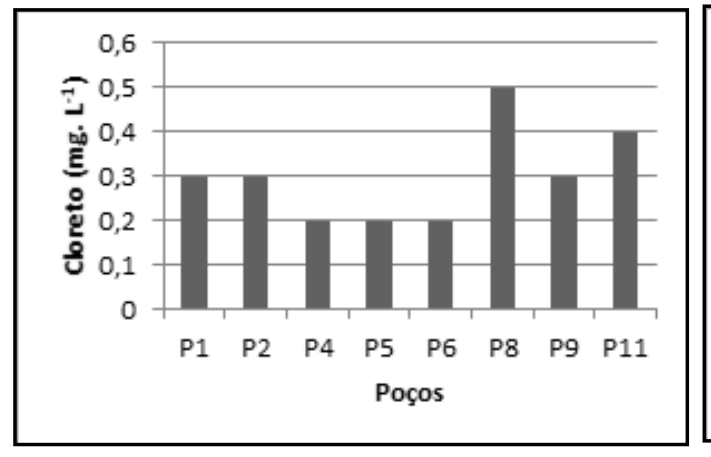

(A)

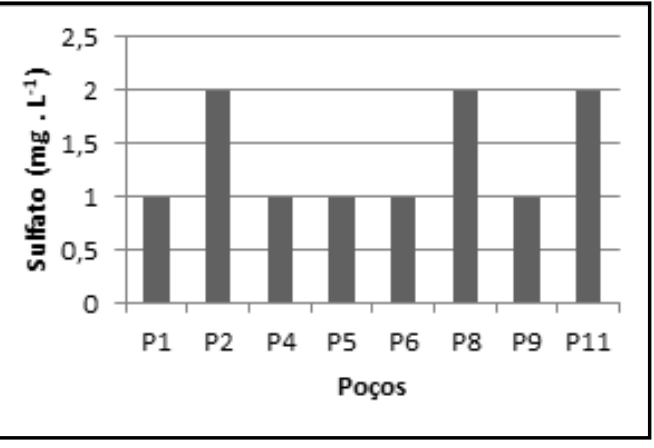

(B)

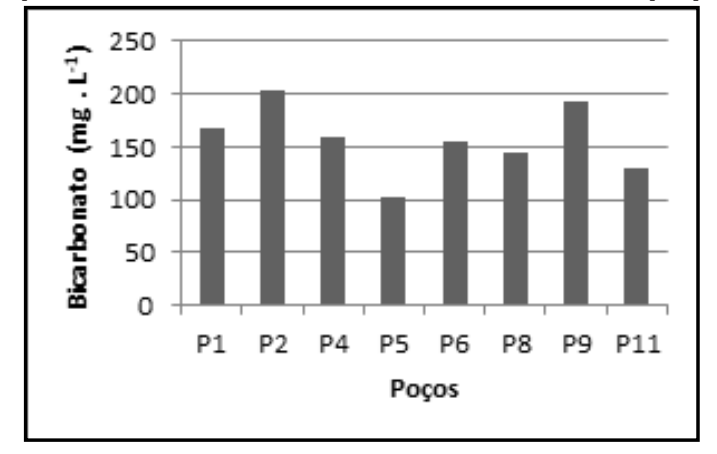

(C)

Fonte: Gomes; Migliorini (2016).

A legislação brasileira, por meio da Portaria no 5 do Ministério da Saúde (BRASIL, 2017) e da Resolução do CONAMA 396/2008 (BRASIL, 2008), fixam o limite máximo de $250 \mathrm{mg} \cdot \mathrm{L}^{-1}$ de sulfato como padrão de potabilidade da água quanto a esse parâmetro.

$\mathrm{Na}$ Figura 5b, é apresentado o gráfico das concentrações de sulfato nos 08 poços analisados neste estudo. Os teores de sulfato variaram de $1 \mathrm{mg} \cdot \mathrm{L}^{-1}$ à $2 \mathrm{mg} \cdot \mathrm{L}^{-1}$, com desvio padrão igual a 0,52 , mediana de 1 , com média de $1,37 \mathrm{mg} \cdot \mathrm{L}^{-1}$, muito abaixo dos limites exigidos pela legislação federal.

O nitrato é um produto do estágio final da oxidação da matéria orgânica, de grande mobilidade, podendo ser removido de camadas superiores do solo para a água. Geralmente é encontrado em teores mínimos em águas subterrâneas; concentrações acima de $5 \mathrm{mg} \cdot \mathrm{L}^{-1}$ podem indicar contaminação de origem antropogênica (CUSTODIO; LLAMAS, 1983). Todas as amostras apresentaram concentrações abaixo do limite de detecção do método empregado $\left(<0,04 \mathrm{mg} \cdot \mathrm{L}^{-1}\right)$.

A alcalinidade representa o teor de substâncias presentes na água com a capacidade de neutralizar determinada quantidade de ácido, ou seja, substâncias que atuam como tampão. Pode ser resultado de íons bicarbonatos, carbonatos e hidróxidos, dependendo do $\mathrm{pH}$. Água com $\mathrm{pH}$ > 9,4 apresenta alcalinidade devido a íons hidróxidos e carbonatos; com $\mathrm{pH}$ entre 8,3 e 9,4 os íons carbonatos e bicarbonatos são os responsáveis pela alcalinidade e; em pH entre 4,4 e 8,3 a alcalinidade é devida somente a íons bicarbonatos (MACÊDO, 2005).

A Figura $5 \mathrm{c}$ apresenta os resultados dos teores da alcalinidade total nos poços do PAG. A alcalinidade é um parâmetro não limitado pela Portaria no 5/2017 do Ministério da Saúde (BRASIL, 2017); porém valores elevados podem conferir sabor amargo à água, sendo assim, recomenda-se limites de alcalinidade aceitáveis até $350 \mathrm{mg} \cdot \mathrm{L}^{-1}$.

Os resultados encontrados nos poços do PAG são semelhantes a outros estudos realizados em Cuiabá (MIGLIORINI, 2000; APOITIA, 2003) com as seguintes médias: $136 \mathrm{mg} \cdot \mathrm{L}^{-1}$ 
e $169,16 \mathrm{mg} \cdot \mathrm{L}^{-1}$ respectivamente. Este trabalho apresenta os seguintes valores estatísticos de alcalinidade total: máximo: 202,50 $\mathrm{mg} \cdot \mathrm{L}^{-1}$, mínimo: $103 \mathrm{mg} \cdot \mathrm{L}^{-1}$, média: $157 \mathrm{mg} \cdot \mathrm{L}^{-1}$, desvio padrão: $32,19 \mathrm{mg} \cdot \mathrm{L}^{-1}$ e mediana: $157,5 \mathrm{mg} \cdot \mathrm{L}^{-1}$.

Os poços com as maiores alcalinidades são os $\mathrm{P} 2$ e P9. Considerando-se os valores de $\mathrm{pH}$ pode-se concluir que a alcalinidade medida é devida somente a íons bicarbonatos.

Como era de se esperar, a relação condutividade x concentração de íons mostrou-se bem interessante neste trabalho, pois, na medida em que se encontrou uma concentração iônica maior, também se observou uma maior condutividade elétrica. Na Figura 3c, são apresentados os valores de condutividade elétrica medidos em campo.

\section{Correlações}

Estudos hidroquímicos buscam correlações entre os parâmetros pesquisados, de forma que sua interpretação aponte sugestões sobre a mineralogia das rochas por onde a água subterrânea percolou no aquífero.

O gráfico resultante da correlação entre cálcio e magnésio (Figura 6a) apresentou um coeficiente correlação de Pearson $r=0,764$, com significância estatística ( $p=0,027)$, demonstrando que o aumento das concentrações de cálcio e magnésio tende a manter uma forte proporcionalidade em todas as amostras, onde o aumento na concentração de um íon explica ou decorre do aumento na concentração do outro íon. Provavelmente essa forte correlação está relacionada à presença de lentes de calcário, muito comum no Grupo Cuiabá.

Entre a condutividade elétrica e o somatório da concentração de todos os íons analisados, a correlação encontrada apresentou $r=0,9828$, e excelente significância estatística $(p=0,0001)$, demonstrando a influência dos íons dissolvidos na água com sua condutividade elétrica. A Figura 6b apresenta o gráfico dessa relação.

Os íons cloreto e sulfato apresentam coeficiente de correlação de Pearson r=0,774, com significância estatística $(\mathrm{p}=0,024)$ o que pode ser explicado pela alta solubilidade e saturação destes ânions no solo. Na Figura 6c é apresentado o gráfico que relaciona os íons cloreto e sulfato.

A Figura 6d traz a correlação entre a Alcalinidade Total, demonstrada pela concentração dos íons bicarbonatos, com o somatório das concentrações dos íons cálcio e magnésio, com forte correlação de Pearson ( $r=0,9536)$ e excelente significância estatística $(0,0002)$, demonstrando que a alcalinidade é causada fortemente por bicarbonatos de cálcio ou de magnésio, nas águas do PAG.

O balanço iônico é um importante instrumento para avaliação dos erros de análises laboratoriais, medida fundamental na validação de estudos hidroquímicos. O erro aceitável do balanço iônico compreende o intervalo entre $\pm 10 \%$. A precisão dos resultados analíticos dos íons maiores foi verificada mediante o cálculo do erro de análise, utilizando o programa Qualigraf ${ }^{\circledast}$, que demonstrou limites toleráveis no balanço iônico, dentro do intervalo aceitável. Também classificou os poços P1, P2, P4, P5, P6, P8 e P11 como bicarbonatada magnesiana, e o $\mathrm{P} 9$ como bicarbonatada cálcica.

Os resultados das concentrações dos íons maiores $\left(\mathrm{em} \mathrm{mEq} \cdot \mathrm{L}^{-1}\right.$ ) foram plotadas no diagrama de Piper, que relaciona a miliequivalência entre os elementos principais: os cátions cálcio, sódio, potássio e magnésio com os ânions cloreto, sulfato, bicarbonato e carbonato.

O diagrama de Piper caracteriza as águas em sulfatadas ou cloretadas cálcicas ou magnesianas, águas sulfatadas ou cloretadas sódicas e águas bicarbonatadas sódicas. Nesse diagrama são plotadas 


\section{Figura 6 - Correlações entre alguns íons analisados em águas subterrâneas do PAG.}

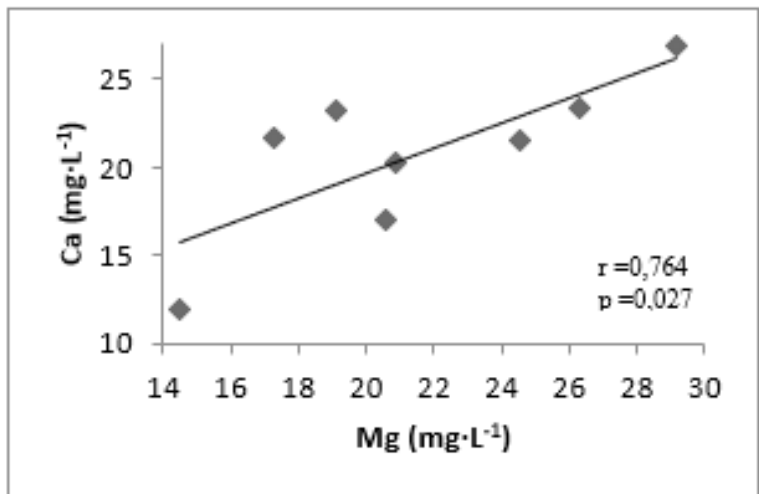

(a)

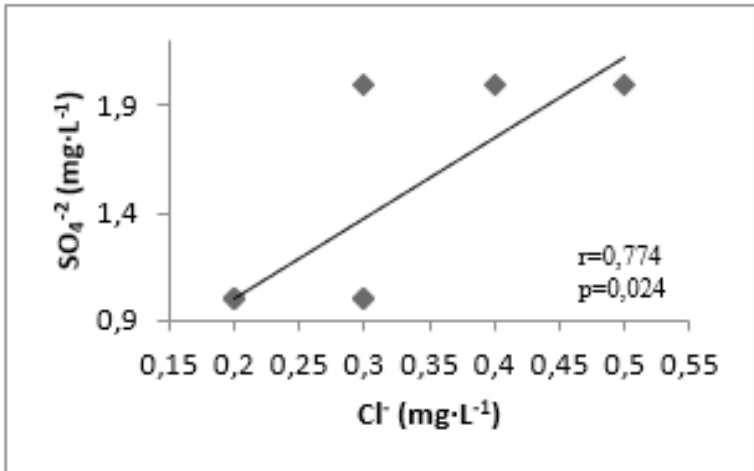

(c)

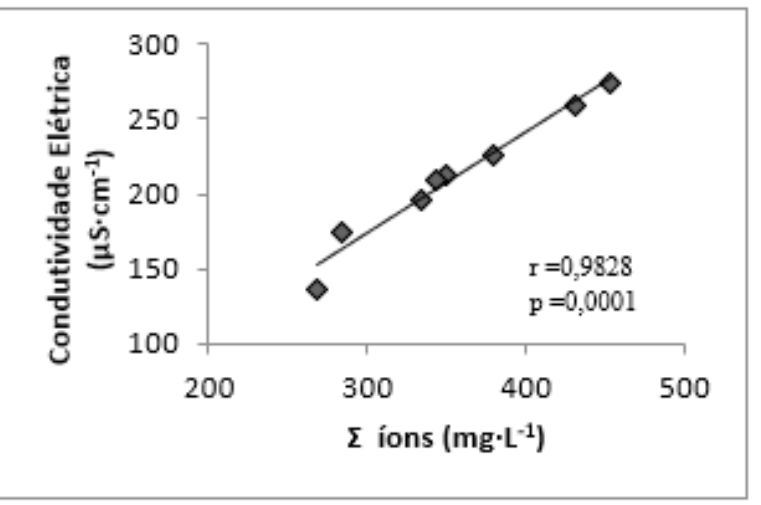

(b)

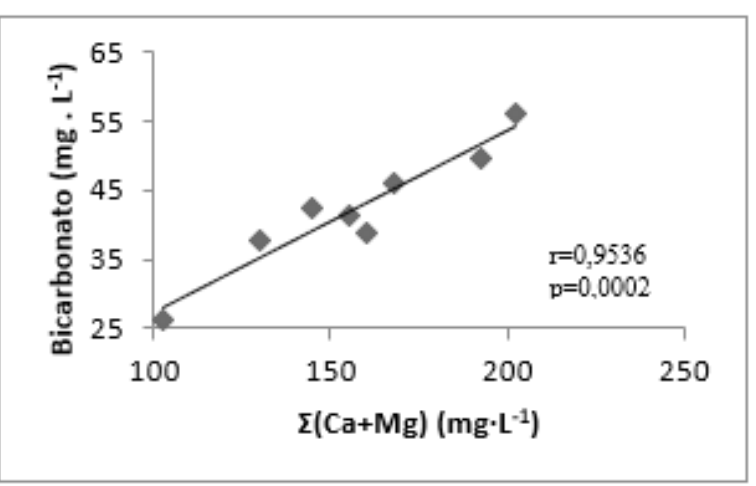

(d)

Fonte: Gomes; Migliorini (2016).

as proporções, com escala correspondente a 100\%, relativas aos íons principais, porém não suas concentrações relativas. No PAG foi encontrado o grupo das águas bicarbonatadas cálcicas ou magnesianas (Figura 7).

No PAG, os assentados trabalham com horticultura e fruticultura, tanto para consumo domiciliar quanto para o comércio em pequena escala. Por isso, este trabalho classificou suas águas para utilização na agricultura, baseando-se na Razão de Absorção de Sódio (RAS) e na condutividade elétrica da água (CE), de acordo com método do United States Salinity Laboratory (USSL). A RAS indica a porcentagem de sódio numa amostra de água, que pode ser absorvido pelo solo, devendo ser mínima para uma menor salinidade (FEITOSA et al., 2008).

Todas as amostras analisadas estão classificadas na faixa $\mathrm{C}_{2}-\mathrm{S}_{1}$ segundo o método do USSL, indicando $\mathrm{C}_{2}$ : águas de média salinidade, que devem ser usadas com precaução, e de preferencia em solos silto-arenosos, siltosos ou areno-argilosos quando houver uma lixiviação moderada do solo, onde podem ser cultivados vegetais de fraca tolerância salina sem perigo de salinização; e $\mathrm{S}_{1}$ : águas com baixo risco de salinização podendo ser utilizadas para quase todos os solos, com baixo risco de formação de teores nocivos de sódio susceptível de troca, valendo-se ao cultivo de quase todos os vegetais (FEITOSA et al., 2008).

Para utilização dessas águas na dessedentação animal, as mesmas foram classificadas segundo Logan (1965), que analisa os valores de sólidos totais dissolvidos (STD). Foi observado que todos os poços possuem água classificada como boa para a dessedentação animal, não apenas pelo teor de STD, como também pela ausência de ferro, nitratos e também com $\mathrm{pH}$ próximo da faixa de neutralidade. 
Figura 7 - Diagrama Triangular de Piper das águas do PAG.

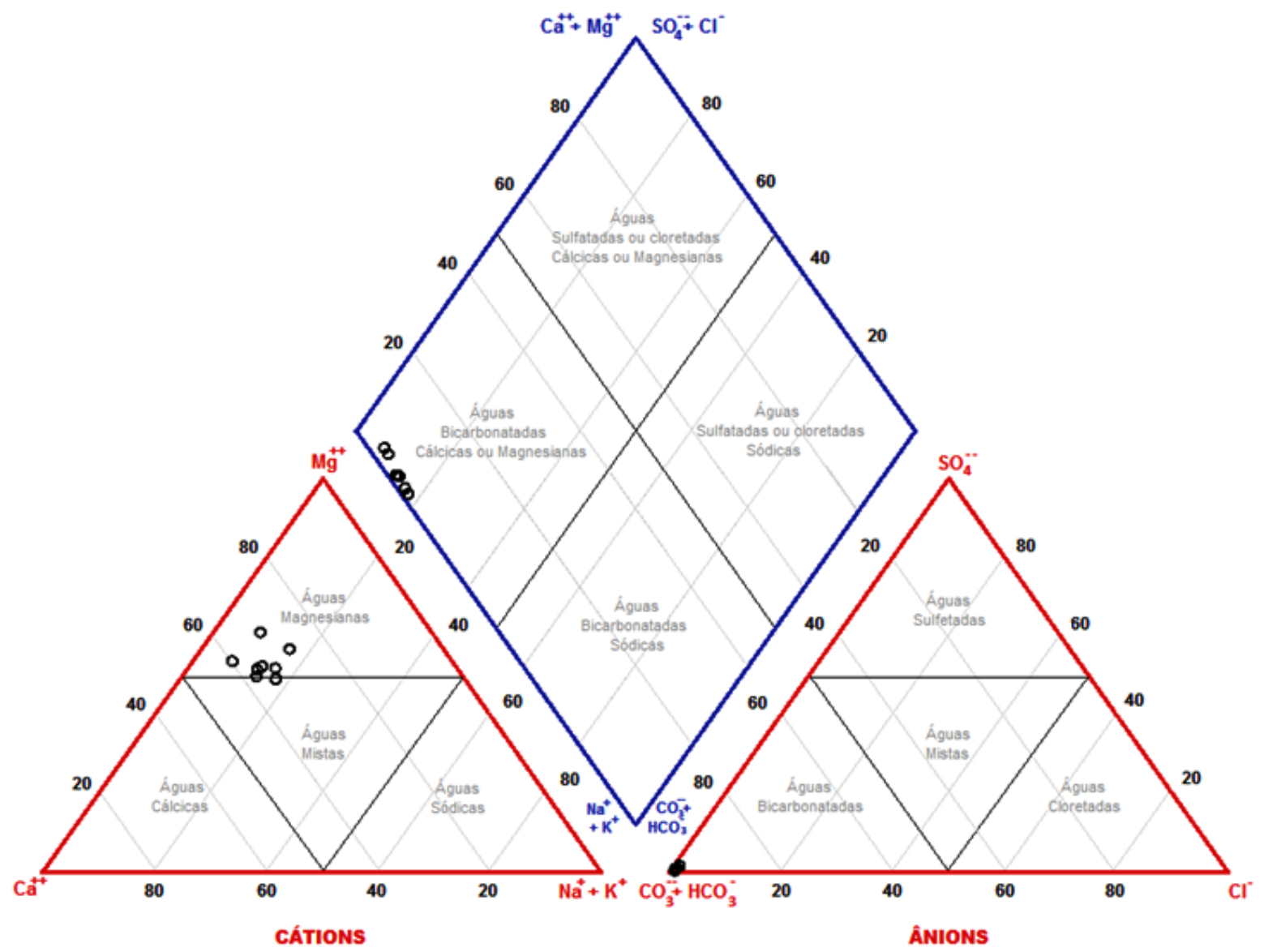

Fonte: Gomes; Migliorini (2016).

\section{Conclusão}

A caracterização hidroquímica das águas subterrâneas no PAG permitiu constatar a existência de dois tipos de águas subterrâneas: águas bicarbonatadas magnesianas e bicarbonatadas cálcicas.

São águas hipotermais, neutras a alcalinas, de boa qualidade físico-química tanto para consumo humano, irrigação quanto para dessedentação animal, devido à baixa concentração de sais dissolvidos.

$\mathrm{A}$ boa correlação entre $\mathrm{Ca} / \mathrm{Mg}$ deve-se, provavelmente, à ocorrência de lente de calcário no Grupo Cuiabá.

Embora haja ocorrência de piritas disseminadas na região, as águas do PAG estão praticamente isentas de ferro, o que é um problema em outras regiões de Cuiabá.

Também é necessário orientação/capacitação aos perfuradores quanto à construção eficaz de poços que permitam seu monitoramento, proteção e manutenção, dedicando atenção especial à descrição do perfil litológico dos poços, documento que geralmente não é encontrado com os proprietários dos poços particulares ou com a empresa estatal que perfurou os poços públicos na região.

\section{Referências Bibliográficas}

ALMEIDA, F. F. M. Geologia do Centro-Oeste Matogrossense. Boletim da Divisão de GOMES, I. M., MIGLIORINI, R. B. 
Geologia e Mineralogia, Rio de Janeiro, v. 215, p.1-133, 1964.

APHA, AWWA, WPCF. Standard Methods for the Examination of Water and Wastwater. 22 ${ }^{\text {nd }}$ ed. Washington, DC: American Public Health Association, 2012.

APOITIA, L. F. M. Caracterização preliminar do quimismo das águas subterrâneas de Cuiabá-MT. 2003. 130 p. Dissertação (Mestrado em Geologia), Departamento de Geologia, Universidade Federal do Paraná, Curitiba, 2003.

BEAL, V. Estratigrafias de sequencias do Grupo Cuiabá, Faixa Paraguai Norte, Mato Grosso. 2013.51 p. Dissertação (Mestrado em Geociências), Departamento de Recursos Minerais, Universidade Federal de Mato Grosso, Cuiabá, 2013.

BRASIL. Ministério do Meio Ambiente. Download de Dados Geográficos. Disponível em: http://mapas.mma.gov.br/i3geo/datadownload.htm. Acesso em: 20 abr. 2015.

BRASIL. Ministério da Saúde. Portaria n. 5, de 28 de setembro de 2017. Disponível em: https://portalarquivos2.saude.gov.br/images/pdf/2018/marco/29/PRC-5-Portaria-deConsolida----o-n---5--de-28-de-setembro-de-2017.pdf. Acesso em 26 nov. 2019.

BRASIL. Conselho Nacional do Meio Ambiente - CONAMA. Ministério do Meio Ambiente. Resolução n. 396, de 3 de abril de 2008. Diário Oficial da União, Brasília, 7 de abril de 2008. Seção I. p. 64-68.

CELIGOI, A. Considerações sobre as análises químicas de águas subterrâneas. Geografia. Londrina, v. 8, n. 1, p 91-97, jan-jun, 1999.

CENTRO REGIONAL DE INFORMAÇÕES DAS NAÇÕES UNIDAS -UNRIC. ONU projeta que população mundial chegue a 8,5 bilhões em 2030. Disponível em: http://www.unric.org/pt/actualidade/31919-onu-projeta-que-populacao-mundialchegue-aos-85-mil-milhoes-em-2030. Acesso em: 30 set. 2015.

COMPANHIA DE TECNOLOGIA DE SANEAMENTO AMBIENTAL-CETESB. Guia nacional de coleta e preservação de amostras: água, sedimento, comunidades aquáticas e efluentes líquidos. Procedimento Técnico. Brasília: CETESB, 2011.

CUSTODIO, E.; LLAMAS, M. R. Hidrología Subterránea. Barcelona: Ediciones Omega S. A., 1983.

EVANS,J.W.The Geology of Mato Grosso (Particularity the region drained by the upper Paraguay). Quartely Journal of the Geological Society, London, v. 50, p. 85-104, 1894.

FEITOSA, F. A. C;. MANOEL FILHO, J.; FEITOSA, E. C.; DEMETRIO, J. G. A. Hidrologia: conceitos e aplicações. 4 ed. Rio de Janeiro: CPRM: LAHID SERVIÇO GEOLOGICO DO BRASIL, 2008. 
FACULDADE DE ENGENHARIA DE ILHA SOLTEIRA - FEIS. Qualidade da água para irrigação. Disponível em: http://www.agr.feis.unesp.br/acagua.htm. Acesso em: 20 out. 2015.

HIRATA, R.; SUHOGUSOFF, A. V. Águas subterrâneas: um importante recurso que requer proteção. Geociências USP, São Paulo, 13 jul. 2003. Disponível em: http://www. igc.usp.br/index.php?id=164. Acesso em: 18 jul. 2016.

INSTITUTO BRASILEIRO DE GEOGRAFIA E ESTATÍSTICA - IBGE. Censo 2000. Disponível em: http://www.ibge.gov.br. Acesso em: fev. 2016.

INSTITUTO BRASILEIRO DE GEOGRAFIA E ESTATÍSTICA - IBGE. Censo 2010. Disponível em: http://www.ibge.gov.br. Acesso em: fev. 2016.

LOGAN, J. Interpretações de análises químicas d'água. Recife: U. S. Agency for International Development, 1965.

LUZ, J. S.; OLIVEIRA, A. M.; SOUZA, J. O.; MOTTA, J. F. M.; TANNO, L. C.; CARMO, L. S., SOUZA, N. B. Projeto Coxipó. DNPM/CPRM v. 1.136 p. Relatório Final. Goiânia, 1980.

MACÊDO, J. A. B. Métodos Laboratoriais de Análises Físico-químicas e Microbiológicas. 3. ed. Belo Horizonte: Conselho Regional de Química-MG, 2005.

MATTHESS, G. The Properties of Groundwater. New York: John Wiley \& Sons, 1982.

MESTRINHO, S. S. P. Geoquímica e Contaminação de Águas Subterrâneas. Ministério de Minas e Energia, Departamento Nacional de Produção Mineral-DNPM, Associação Brasileira de Águas Subterrâneas-ABAS, Recife-PE, 1997.

MIGLIORINI, R. B. Hidrogeologia em meio urbano. Região de Cuiabá e Várzea Grande-MT. São Paulo-SP. 2000. 146 p. Tese (Doutorado em Geociências), Instituto de Geociências, Universidade de São Paulo. São Paulo, 2000.

MIGLIORINI, R. B. ; SILVA, A. A. K. E. Hidrogeologia em rochas fraturadas. Estudo do Grupo Cuiabá. In: Joint World Congress on Groundwater, 1, 2000. Fortaleza. Anais. Fortaleza, v. 11.2000.

MÖBUS, G. QUALIGRAF. Programa para Análise da Qualidade de água. v. 1.17, Fundação Cearense de Meteorologia e Recursos Hídricos, 2014. Disponível em: http:// www3.funceme.br/qualigraf/mi/qualigraf/mi/midia/show/3. Acesso em: 05 maio 2014.

PIPER, A. M. A graphic procedure in the geochemical interpretation of water analysis. Transactions American Geophysical Union, v. 25, p. 914-928, 1944.

RAMAGE, L. Hidrogeoquímica do sistema aquífero granular cenozoico do município de Porto Alegre, RS. 2005. 111 p. Dissertação (Mestrado em Geociências), Instituto de 
Geociências, Universidade Federal do Rio Grande do Sul, Porto Alegre, 2005.

RAVE, J. C. G. Geologia, geoísica, hidrogeoquímica y isótopos, como herramientas para definir un modelo conceptual hidrogeológico, caso de aplicación: Acuífero costeiro del município de Turbo. 2009. 296 p. Dissertação (Maestria en Inginiería - Recursos Hidráulicos) Facultad de Minas, Universidad Nacional de Colombia, Medellín, 2009.

RICHARDS, L. A. Diagnosis and improvement of saline and alkali soils. Washington, D.C: United States Salinity Laboratory - USSL. Department of Agriculture, Handbook 60, 1954.

SANTOS, A. C. Noções de Hidroquímica. In: FEITOSA, F. A. C.; FILHO, J. M. Hidrogeologia - Conceitos e Aplicações. 2 ed. Fortaleza: CPRM REFO, LAHID-UFPE, 2000.

SILVA, L. P. G; SILVA, J. I. S.; MELO, E. J.; SILVA, E. E. P. Potencial químico de neutralização do calcário em solos ácidos. Enciclopédia Biosfera, Suplemento Especial, Goiânia, v. 5, n. 8, 2009.

SISTEMA NACIONAL DE INFORMAÇÕES SOBRE SANEAMENTO - SNIS. Diagnóstico de Serviços de Água e Esgoto 2014. Disponível em http://www.snis.gov. br/diagnostico-agua-e-esgitos/diagnostico-ae-2014. Acesso em: jul. 2016.

SOUZA, N. B. O Grupo Cuiabá na área do Projeto Coxipó. Estratigrafia e Potencialidade Econômica. In: Simpósio de Geologia do Centro-Oeste, 1, 1981, Goiânia. Anais. Goiânia: Atas SBG, 1981. p. 226-239.

WORLD HEALTH ORGANIZATION - WHO. Chloride in Drinking-water. 2003. Disponível em: http://www.who.int/water_sanitation_health/publications/chloride/en/. Acesso em: set. 2015.

ZIMBRES, E. Meio Ambiente Pro Br. Química da Água Subterrânea. Disponível em: http://meioambiente.pro.br/agua/guia.htm. Acesso em: 10 set. 2015. 